\title{
Mortality following emergency laparotomy: a Swedish cohort study
}

\author{
Terje Jansson Timan ${ }^{1,2,3^{*}}$, Gustav Hagberg ${ }^{4}$, Ninni Sernert ${ }^{2,5}$, Ove Karlsson ${ }^{3,6}$ and Mattias Prytz ${ }^{1,2,4}$
}

\begin{abstract}
Background: Emergency laparotomy (EL) is a central, high-risk procedure in emergency surgery. Patients in need of an EL present an acute pathology in the abdomen that must be operated on in order to save their lives. Usually, the underlying condition produces an affected physiology. The perioperative management of this critically ill patient group in need of high-risk surgery and anaesthesia is challenging and related to high mortality worldwide. However, outcomes in Sweden have yet to be studied. This retrospective cohort study explores the perioperative management and outcome after 710 ELs by investigating mortality, overall length of stay (LOS) in hospital, need for care at the intensive care unit (ICU), surgical complications and a general review of perioperative management.

Methods: Medical records after laparotomy was retrospectively analysed for a period of 38 months (2014-2017), the emergency cases were included. Children ( $<18$ years), aortic surgery, second look and other expected reoperations were excluded. Demographic, management and outcome data were collected after an extensive analysis of the cohort.

Results: A total of 710 consecutive operations, representing 663 patients, were included in the cohort (mean age 65.6 years). Mortality (30 days/1 year) after all operations was $14.2 \%$ and $26.6 \%$ respectively. The mean LOS in hospital was 12 days, while LOS in the ICU was five days. Of all operations, 23.8\% patients were admitted at any time to the ICU postoperatively and the 30-day mortality seen among ICU patients was $37.9 \%$. Mortality was strongly correlated to existing comorbidity, high ASA classification, ICU care and faecal peritonitis. The mean/median time from notification to operate until the first incision was 3:46/3:02 $\mathrm{h}$ and $87 \%$ of patients had their first incision within $6 \mathrm{~h}$ of notification.
\end{abstract}

Conclusions: In this present Swedish study, high mortality and morbidity were observed after emergency laparotomy, which is in agreement with other recent studies.

Trial registration: The study has been registered with ClinicalTrials.gov (NCT03549624, registered 8 June 2018).

Keywords: Acute surgery, Emergency laparotomy, Acute abdomen, Outcome, Mortality, Intensive care, ICU, Perioperative management

\section{Background}

General surgical procedures account for a large proportion of the care provided in hospitals in many countries [1]. Compared with emergency surgery, patients undergoing elective surgical procedures have

*Correspondence: terje.jansson.timan@vgregion.se

${ }^{1}$ Department of Surgery, Institute of Clinical Sciences, Sahlgrenska

Academy, University of Gothenburg, Gothenburg, Sweden

Full list of author information is available at the end of the article a much lower mortality and morbidity rate. Elective surgery constitutes the vast majority of general surgical procedures $[2,3]$. Acute abdominal surgery can be stratified by risk (high and low risk), where high-risk procedures require a significant amount of hospital resources and are associated with high mortality and morbidity $[4,5]$. Emergency laparotomy (EL), a highrisk procedure, is a cornerstone of emergency surgery and is often performed when the clinically impaired 
patient requires urgent surgery for an acute abdominal condition. Although the underlying pathology varies, patients undergoing EL can be seen as a subgroup in the field with high mortality, especially among the elderly with comorbidity $[6,7]$. International studies report a $7-21 \%$ short-term mortality rate, a long overall stay in hospital and a large number of ICU admissions for patients undergoing EL [6, 8-11].

Although patient demographics vary, a typical case may generally be an elderly patient with comorbidities and a pathological abdominal condition affecting organ function and generating critical illness, where the necessary action is an EL. It is a challenge for healthcare providers to handle these complex cases to ensure the best possible outcome [12]. In recent years, great efforts have been made to improve the postoperative outcome for patients undergoing an EL [11, 13, 14]. These studies indicate that the postoperative patient outcome can be improved by standardised perioperative management, a care bundle, with several key actions and measures, together with a high level of competence in the responsible surgeon and anaesthesiologist.

To the best of our knowledge, outcome after EL has not recently been studied in large Swedish cohorts. In this cohort study, we aim to explore the outcome after EL in 710 consecutive patients with respect to primary (30-day mortality) and secondary endpoints (overall hospital stay, number of ICU admissions/days in the ICU and surgical complications). In addition, the study also examines the surgical and anaesthesiological perioperative management of the cohort. During the current study period, no standardisation of perioperative management was carried out.

\section{Methods}

\section{Study design}

This single-centre retrospective cohort study aims to explore the outcome after EL in 710 consecutive operations (Fig. 1). Data on perioperative management and the demographic structure of the cohort were collected.

During the study period (20 August 2014 to 20 October 2017), there was no standardisation of perioperative management for these patients at our institution, NU-Hospital Group (NÄL; Trollhättan, Sweden). Perioperative management was at the discretion of the responsible surgeon and anaesthesiologist. Important management factors, such as the start of i.v. antibiotics, perioperative monitoring and postoperative assessment by the anaesthesiologist, could therefore vary. Even critical factors, like the time to surgery and perioperative interventions, differed between patients.

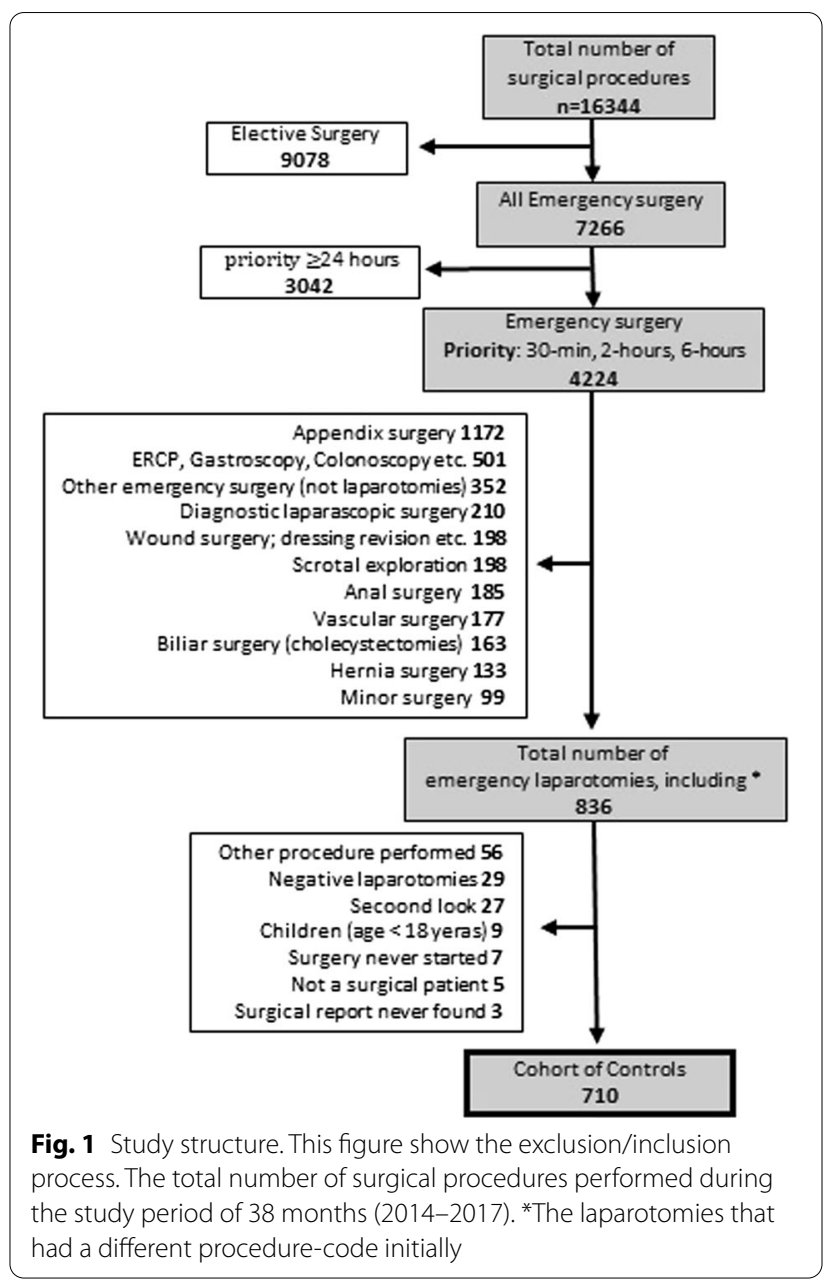

\section{Patient selection}

The study period for this control cohort study was chosen (Fig. 1) because the standardisation of EL at NÄL started in February 2018. The current study aims to investigate the outcome before standardisation. The medical records for all cases undergoing EL during the study period were scrutinised. All adult patients ( $\geq 18$ years) with a priority of six hours or less to the start of surgery were included. The priority for surgery was according to the discretion of the surgeon responsible for the patient and based on the patient's clinical status and suspected underlying pathology. There was at the time no written standardisation for this decision in the department. Exclusions comprised acute aortic surgery, children (0-17 years), negative laparotomies (i.e. when no intra-abdominal pathology or injury was found), planned reoperations (for example, second-look surgery) and expected reoperations shortly after EL (when the patient does not improve clinically postoperatively). 


\section{Demographic variables}

To assess comorbidity, medical records were scrutinised for smoking, obesity, diabetes, renal failure, heart failure, ischaemic heart disease (IHD) and COPD (Chronic Obstructive Pulmonary Disease). In addition, data on current cancer diagnoses were collected and these data represent patients who have a registered cancer diagnosis for at least one hospital admission from three years before until one year after the date of surgery. For patients who underwent multiple operations, the time span is from three years before the first operation until one year after the last.

Pathological findings, such as mechanical ileus, peritonitis, ischaemic or gangrenous bowel, bleeding, perforation or trauma, supplemented the information. There were two possible ways of tracking the data. Firstly, the medical records where the prevalence of current diseases and treatments was stated. Secondly, the anaesthesiologist's preoperative assessment from the surgical record, which stated current diseases, medications and results in an American Society of Anaesthesiologists (ASA) classification $[15,16]$. An ASA classification was missing for 25 cases and a senior consultant at the Department of Anaesthesiology classified the missing cases retrospectively. Besides comorbidity, data for age, gender, height and weight were collected.

\section{Management variables}

To illustrate the perioperative management, three types of variable were required: time-point variables, management variables and competence information.

Analysis of important time points: in the present study, the start of patient management was defined as the time of notification to operate. The time from the start until the first incision was analysed for the three priority categories, i.e. start within $30 \mathrm{~min}, 2 \mathrm{~h}$ or $6 \mathrm{~h}$. The exact time points for the start of anaesthesia, the start of surgical operation (first incision), the end of operation, the start and end of care at the postoperative recovery unit, as well as the start and end dates for ICU care and overall hospital stay, were defined.

To assess the overall management performed, the surgical report and the computerised operational planning system $\left(\mathrm{Orbit}^{\odot}\right)$ was used. The surgical procedures, such as adhesiolysis, intestinal resections, stoma, anastomoses and the removal of other organs, were summarised. The anaesthesiological assessment and interventions included data on the induction drug, treatment with vasopressors, arterial line insertion, application of epidural anaesthesia and treatment with perioperative antibiotics.

The level of competence in the operating theatre was divided into the three categories of registrar, specialist and senior consultant.

\section{Outcome variables}

The main outcome (i.e. short-term mortality) was defined as mortality within 30 days from the first incision. The secondary outcomes included long-term mortality (within 90 and 365 days), overall LOS in hospital and the ICU and the need for intensive care. The Clavien-Dindo (C-D) classification system was used to identify and classify surgical complications. The cohort was divided into two groups representing less severe $(\mathrm{C}-\mathrm{D}$ score of 1 to 3a) and major (C-D score of $3 \mathrm{~b}$ to 5) complications [17]. The rationale behind this grouping is that C-D 1-3a are complications that require drug treatment, blood products or diagnostic procedures. The group with major complications has either undergone repeated surgery and intensive care or expired.

\section{Data and statistical analysis}

In the inclusion phase, each patient's medical record data were scrutinised. Then, in the processing phase, all the data were analysed and de-identified. All the variable data were presented as frequency and percentage (n, \%). Continuous variables are expressed as the mean and median following interquartile ranges. A univariate analysis with the $\mathrm{chi}^{2}$ test was performed. P values of $<0.05$ were considered statistically significant.

Statistical analyses were performed using IBM SPSS statistics version 25.0.

\section{Results}

\section{Demographic data}

A total of 710 consecutive operations, representing 663 patients, were included, with a female predominance (55.4\%) and mean age of 65.7 (18-96) years. (Table 1).

In $51.8 \%$ of the operations, the patient suffered from one or more of the defined comorbidities (smoking, diabetes, renal failure, heart failure, IHD, COPD and obesity). When the prevalence of the different comorbidities was explored, it was found in between 8.0 and 13.0 per cent respectively. The group with a cancer diagnosis accounts for almost a third of the cohort with a mean age of 72.7 years (Table 1 ).

For the cohort, bowel obstruction represented the most common underlying pathology in $56.7 \%$ of all operations, with the small intestine as the most common site. Different intestinal perforations were seen in $30.5 \%$ of the cases and peritonitis in $26.3 \%$ (Table 2).

The cohort contains 41 patients who had EL more than once (1 patient had 4 operations, 4 patients had 3 operations and 36 patients had 2 operations) and these 41 patients therefore represent 88 operations. The condition for including this category of cases is that the procedure was unexpected in the sense that the patient improved clinically from the acute condition to the point of being 
Table 1 Demography. Baseline characteristics for all operations

\begin{tabular}{|c|c|c|c|}
\hline & & n (\%) & Mean age \\
\hline Alloperations & & $710(100 \%)$ & \\
\hline \multirow[t]{2}{*}{ Gender } & Female & $393(55.4)$ & 66.2 \\
\hline & Male & $317(44.6)$ & 65.0 \\
\hline Age & All operations & 18 to 96 years & 65.7 \\
\hline \multirow[t]{5}{*}{ ASA-classification } & ASA-1 & $72(10.1)$ & 49.1 \\
\hline & ASA-2 & $247(34.8)$ & 59.0 \\
\hline & ASA-3 & $282(39.7)$ & 71.9 \\
\hline & ASA-4 & $98(13.8)$ & 75.8 \\
\hline & ASA-5 & $11(1.5)$ & 72.5 \\
\hline \multirow[t]{3}{*}{ Priority } & $<30 \min$ & $25(3.5)$ & 53.6 \\
\hline & $<2-h$ & $272(38.3)$ & 65,3 \\
\hline & $<6 h$ & $413(58.2)$ & 66.7 \\
\hline \multirow[t]{2}{*}{ Surgery } & Primary & $597(84.1)$ & 65.8 \\
\hline & Reoperation & $113(15.9)$ & 64.9 \\
\hline \multirow[t]{10}{*}{ Comorbidity } & Yes (one or more) & $388(51.8)$ & 68.1 \\
\hline & No & $342(48.2)$ & 63.0 \\
\hline & Obesity & $88(12.4)$ & 55.9 \\
\hline & Smoker & $92(13.0)$ & 62.1 \\
\hline & Renal failure & $90(12.7)$ & 77.1 \\
\hline & $\mathbb{H D}$ & $84(11.8)$ & 77.0 \\
\hline & COPD & $57(8.0)$ & 74.3 \\
\hline & Heart failure & $63(8.9)$ & 78.4 \\
\hline & Diabetes & $82(11.5)$ & 72.3 \\
\hline & $\mathrm{BMI} n=640$ & Mean 25.57 & \\
\hline Cancer diagnosis $^{\mathrm{a}}$ & Yes & $218(30.7)$ & 72.7 \\
\hline
\end{tabular}

ASA American society of anaesthesiologist-classification of comorbidity. Priority, for emergency the guideline to start of surgery. Obesity classified as $\mathrm{BMI}>30$. $I H D$ ischemic heart disease. COPD chronic obstructive pulmonary disease. $B M I$ length and weight was detected in 640 cases

${ }^{a}$ Cancer diagnosis of any kind from 3 years before until 1 year after surgery

discharged/or ready for discharge, from the hospital, but then suffered a new event that mandated an EL. The time span could be weeks, months or years after the index emergency laparotomy. In cases where this occurred, the mortality variable has been adjusted so that an expiry can only be attributed as a result to the last EL. However, variables for overall hospital stay, ICU time or other morbidity have been left unchanged. The cohort thus contains 663 unique patients.

\section{Perioperative management analysis}

The time from notification to operate until the first incision was analysed; the 30-min group's mean time to start was 1:01 (hours:minutes), the two-hour priority group had a mean start of $2: 33 \mathrm{~h}$ and the mean for six-hours' priority was $4: 43$. The overall mean for the entire cohort was 3:46 and, in $87 \%$ of all cases, the first incision was made within six hours (Table 3). The most common level of surgical competence in the operating
Table 2 Case demography presented as pathology:

\begin{tabular}{lc}
\hline & n (\%) \\
\hline All operations & $710(100 \%)$ \\
All lleus & $403(56.7)$ \\
Ileus-small intestine & $334(47.0)$ \\
Ileus-colon & $69(9.7)$ \\
All intestinal perforations & $217(30.5)$ \\
Perforated colon & $60(8.5)$ \\
Perforated small intestine & $80(11.3)$ \\
Gastric perforation & $56(7.9)$ \\
Anastomosis leakage & $21(3.0)$ \\
Peritonitis & $187(26.3)$ \\
Faecal peritonitis & $57(8.0)$ \\
Purulent peritonitis & $43(6.1)$ \\
Other peritonitis & $87(12.3)$ \\
Intestinal ischemia/gangrene & $81(11.4)$ \\
Intraabdominal bleeding & $43(6.1)$ \\
Trauma laparotomy & $21(3.0)$ \\
\hline
\end{tabular}

This table is a presentation of the pathology that represent the underlying need for surgery among the 710 operations

Table 3 In hospital management-time data

\begin{tabular}{lcll}
\hline & $\mathbf{n}$ & Mean (median, i.q.r) & Total \\
\hline & & (Days:hours) & (Days) \\
Overall hospital stay & 710 & $12: 03(7: 12,9: 01)$ & 8617 \\
All ICU admissions & 169 & $\begin{array}{l}\text { 5:10 }(2: 03,5: 19) \\
\text { (Hours:minutes) }\end{array}$ & 918 \\
& & (Hours) \\
Surgical operation time & 710 & $1: 30(1: 21,1: 00)$ & 1065 \\
Care at recovery ward & 585 & $7: 36(5: 50,5: 24)$ & 4446 \\
Priority & & & \\
$\quad<30$ min & 25 & $1: 01(0: 45,1: 08)$ & \\
$<$ <-h & 272 & $2: 33(2: 16,1: 25)$ & \\
$\quad<6-h$ & 413 & $4: 43(3: 58,2: 42)$ & \\
All operations & 710 & $3: 46(3: 02,2: 40)$ & \\
\hline
\end{tabular}

This table is a summary of the length of stay (LOS) in hospital, LOS at ICU and LOS at recovery ward

Total column for overall hospital stays represents all hospital days for all cases in the study (8617 days), including days at the ICU, hours of surgery and in recovery ward. Care at recovery ward does not include cases admitted to ICU directly from theatre

Priority shows time from booking of the operation to first incision, related to priority. i.q.r interquartile range

theatre (OT) was a senior consultant (63.6\%) with a registrar in $8.6 \%$ of all operations. For anaesthesiologists, the presence of a senior consultant in theatre was seen in $42.0 \%$ of all cases, while the figure for registrars was $38.7 \%$ (Table 4 ). The 30-day and one-year mortality for patients who received intestinal anastomosis were $10.1 \% / 20.8 \%$ and for intestinal stoma $18.0 \% / 41.6 \%$ respectively (Table 5 ). 
Table 4 Operation theatre management

\begin{tabular}{lc}
\hline & $\mathbf{n}(\%)$ \\
\hline Primary surgery & $597(84.1)$ \\
Reoperation & $113(15.9)$ \\
Surgical procedure & \\
All intestinal resections & $252(35.5)$ \\
Resection of small intestine & $155(21.8)$ \\
Resection of colon & $84(11.8)$ \\
Resection of small intestine and colon & $14(2.0)$ \\
Resection of other abdominal organ & $15(2.1)$ \\
Intestinal stoma & $178(25.1)$ \\
Intestinal anastomosis & $159(22.4)$ \\
Adhesiolysis & $320(45.1)$ \\
Anaesthesiologic care & \\
Induction drug propofol & $593(83.5)$ \\
Induction drug ketamine and propofol & $52(7.3)$ \\
Induction drug ketamine & $62(8.7)$ \\
Thoracic epidural anaesthesia & $477(67.2)$ \\
Treated with vasopressor infusion & $505(71.1)$ \\
Arterial-line inserted & $253(35.6)$ \\
Anaesthesiologic complication- aspiration & $5(0.7)$ \\
Perioperative treatment with antibiotics & $555(78.2)$ \\
Level of competence in the OTa & \\
Surgical registrar & $61(8.6)$ \\
Specialist in surgery & $196(27.8)$ \\
Senior consultant in surgery & $450(63.6)$ \\
Anaesthesiologic registrar & $273(38.7)$ \\
Senecialist in anaesthesiology consultant in anaesthesia & $136(19.3)$ \\
\hline & $296(42.0)$ \\
\hline
\end{tabular}

This table shows the management variables examined

OT operation theatre

${ }^{\text {a }}$ Missing value. Surgery $n=3$, Anaesthesiology $n=5$

\section{Outcome analysis}

The overall short-term mortality (30 days) following the 710 ELs in 663 patients was $14.2 \%$, while long-term mortality (365 days) was $26.6 \%$ (Table 5). The group with ICU admission at any time during the hospital stay showed a 30 -day mortality rate of $37.9 \%$ and this group $(n=169)$ accounts for almost a quarter (23.8\%) of the cohort (Table 5). In the group that underwent multiple surgeries (41 patients and 88 operations), three patients died within 30 days of surgery; in one case there were only weeks between the procedures and the mortality for the first EL was adjusted. However, the short-term mortality in this group is low compared with the entire cohort; if calculated on all 88 operations, it is $3.4 \%$ and, if calculated on the 41 patients, it is $7.3 \%$. Overall mortality is presented in relation to all 88 operations (Table 6).

In the univariate analysis, mortality was strongly correlated to ASA classification, ICU care, all kinds of peritonitis, IHD, renal failure, heart failure, COPD and cancer diagnosis. Gender was not correlated to mortality (Table 7). Dividing the cohort into groups based on surgical complications (i.e. minor and major complications) revealed that the minor group (Clavien-Dindo score of 1 to $3 a$ ) represented $62.0 \%$ of the cohort (Table 8 ).

\section{Discussion}

The current study investigates the outcome (i.e. mortality, overall LOS in hospital, the need for intensive care and complications) and perioperative management (i.e. surgical care, anaesthesiological care, time to first incision and timepoint analysis) in a cohort of adult patients undergoing EL.

The overall short-term mortality after EL is $14.2 \%$, which is comparable to recent studies in the field (range from 7 to $21 \%$ ) $[6,8,10,13,14,18]$. The mean overall LOS in hospital was just over 12 days, which is slightly shorter than other cohorts $[8,13]$. Almost a quarter $(23.8 \%)$ of the patients were admitted to the ICU at any time, with a mean ICU stay of almost five and a half days. In the Danish study by Tengberg et al., $21.8 \%$ of the patients in a similar cohort of controls were admitted to the ICU during their hospital stay [13]. The short-term mortality for the cohort admitted to the ICU was $37.9 \%$, which is at the same level as previous studies [10, 19].

Cohort demographics are similar to several others, although the mortality in different studies varies and this cohort shows a mortality somewhere in the middle segment of those reported [6, 8, 10,13,18-20]. Given that the mortality after emergency laparotomy is so high, it is desirable to try to improve the outcome. The importance of working on this issue cannot be overemphasized.

The perioperative outcome analysis shows a significant association with comorbidity, critical illness, old age and a cancer diagnosis in relation to mortality. Previous studies also show a correlation between mortality and ASA classification, as well as ICU admissions [10, 13]. The data demonstrate the widely accepted fact that the elderly who carry a greater disease burden run a high risk of having a poorer outcome postoperatively [6]. This is also supported by the large difference in short-term mortality among the different age groups in the cohort. Furthermore, almost half the patients appear not to have any comorbidity. This is perhaps somewhat underestimated, as our analysis of existing comorbidity was limited to obesity, smoking, renal failure, IHD, heart failure and diabetes. As a result, several patients may be registered as "None" in the variable of comorbidity and still carry a significant disease burden (e.g. neurological and psychiatric conditions).

Data on medical competence in the OT show a clear difference in formal competence between surgeons and 
Table 5 Outcome related to management

\begin{tabular}{|c|c|c|c|c|c|}
\hline \multirow[t]{2}{*}{$\begin{array}{l}\text { Mortality } \\
\text { n (\%) }\end{array}$} & & \multirow{2}{*}{$\begin{array}{l}\text { Total number } \\
\text { in the cohort }\end{array}$} & \multirow{2}{*}{\multicolumn{2}{|c|}{$\begin{array}{l}\text { 30-days 365-days } \\
\text { Accumulated } \\
\text { mortality n (\%) }\end{array}$}} & \multirow[t]{2}{*}{ Not deceased } \\
\hline & & & & & \\
\hline \multicolumn{2}{|l|}{ All operations } & 710 & $101(14.2)$ & $189(26.6)$ & $521(73.4)$ \\
\hline \multirow[t]{3}{*}{ Priority } & $<30 \min$ & 25 & $6(24.0)$ & $7(28.0)$ & $18(72.0)$ \\
\hline & $<2-h$ & 272 & $59(21.7)$ & $87(32.0)$ & $185(68.0)$ \\
\hline & $<6-h$ & 413 & $36(8.7)$ & $95(23.0)$ & $318(77.0)$ \\
\hline \multicolumn{6}{|l|}{ Surgical procedure } \\
\hline \multirow[t]{3}{*}{ Intestinal resection } & Small intestine & 155 & $20(12.9)$ & $34(21.9)$ & $121(78.1)$ \\
\hline & Colon & 84 & $16(19.0)$ & $29(34.5)$ & $55(65.5)$ \\
\hline & Small intestine and colon & 14 & $6(42.9)$ & $7(50.0)$ & $7(50.0)$ \\
\hline \multicolumn{2}{|l|}{ Intestinal anastomosis } & 159 & $16(10.1)$ & $33(20.8)$ & $126(79.2)$ \\
\hline \multicolumn{2}{|l|}{ Intestinal stoma } & 178 & $32(18.0)$ & $74(41.6)$ & $104(58.4)$ \\
\hline \multicolumn{2}{|l|}{ Adhesiolysis } & 320 & $36(11.3)$ & $79(24.7)$ & $241(75.3)$ \\
\hline \multicolumn{2}{|l|}{ Resection of abdominal organ } & 15 & $4(26.7)$ & $8(53.3)$ & $7(46.7)$ \\
\hline \multicolumn{6}{|l|}{ Anaesthesiologic care $e^{a}$} \\
\hline \multicolumn{2}{|l|}{ Induction drug propofol } & 592 & $53(9.0)$ & $122(20.6)$ & $470(79.4)$ \\
\hline \multicolumn{2}{|l|}{ Induction drug ketamine and propofol } & 52 & $15(28.8)$ & $26(50.0)$ & $26(50.0)$ \\
\hline \multicolumn{2}{|l|}{ Induction drug ketamine } & 62 & $31(50.0)$ & $39(62.9)$ & $23(37.1)$ \\
\hline \multicolumn{2}{|l|}{ Thoracic epidural anaesthesia } & 477 & $42(8.8)$ & $99(20.8)$ & $378(79.2)$ \\
\hline \multicolumn{2}{|l|}{ Treated with vasopressor infusion } & 505 & $94(18.6)$ & $164(32.5)$ & $341(67.5)$ \\
\hline \multicolumn{2}{|l|}{ A-Line inserted } & 253 & $55(21.7)$ & $100(39.5)$ & $153(59.5)$ \\
\hline \multicolumn{2}{|l|}{ Anaesthesiologic complication- aspiration } & 5 & $3(60.0)$ & $4(80.0)$ & $1(20.0)$ \\
\hline \multicolumn{2}{|l|}{ Treatment with antibiotics } & 555 & $84(15.1)$ & $162(29.2)$ & $393(70.8)$ \\
\hline \multicolumn{6}{|l|}{ Competence } \\
\hline \multirow[t]{6}{*}{ Highest level of competence in the operation theatre ${ }^{b}$} & Surgical registrar & 61 & $5(8.2)$ & $12(19.7)$ & $49(80.3)$ \\
\hline & Specialist in surgery & 196 & $19(9.7)$ & $37(18.9)$ & $159(81.1)$ \\
\hline & Senior consultant_-surgery & 450 & $76(16.9)$ & $138(30.7)$ & $312(69.3)$ \\
\hline & Anaesthesiologic registrar & 273 & $30(11.0)$ & $72(26.4)$ & $201(73.6)$ \\
\hline & Specialist in anesthesiology & 136 & $18(13.2)$ & $28(20.6)$ & $108(79.4)$ \\
\hline & Senior consultant-anaesthesia & 296 & $50(16.9)$ & $86(29.1)$ & $210(70.9)$ \\
\hline \multicolumn{6}{|l|}{ ICU } \\
\hline \multicolumn{2}{|l|}{ All ICU admissions ${ }^{c}$} & $169(23.8)$ & $64(37.9)$ & $88(52.1)$ & $81(47.9)$ \\
\hline \multicolumn{2}{|l|}{ Direct ICU admission from operation theatre } & $126(17.7)$ & $56(44.4)$ & $71(56.3)$ & $55(43.7)$ \\
\hline
\end{tabular}

Priority, for emergency the guideline from notification to operate until first incision

${ }^{\text {a }}$ Missing value induction drug $\mathrm{n}=4$

${ }^{b}$ Missing value. Surgery $n=3$, Anesthesiology $n=5$

${ }^{c}$ All ICU admissions represents all admissions for a patient to ICU during hospital stay after emergency laparotomy

anaesthesiologists. The finding indicates that, to a large extent, junior anaesthesiologists manage patients undergoing major surgery and anaesthesia by themselves. However, for both surgeons and anaesthesiologists, the short-term mortality is lowest in the group of junior physicians, indicating that the critically ill patients were managed by a more senior colleague.

As expected, short-term mortality is higher in the groups where surgery was deemed more urgent (i.e. operation planned within $30 \mathrm{~min}$ or $2 \mathrm{~h}$ ). This most probably represents the seriousness of the underlying condition, as well as the physical condition of the patient at the time of decision-making. Long-term mortality differs less between the priority groups, thereby indicating that other factors, such as age, underlying malignant disease and so on, are important for long-term survival. Furthermore, we can see from our data that the patients who received intestinal anastomosis have a clearly lower short and long-term mortality and that the patients who underwent procedure with intestinal stoma formation show a clearly 
Table 6 Outcome related to demography for all operations

\begin{tabular}{|c|c|c|c|c|c|}
\hline & & $\begin{array}{l}\text { Total number in } \\
\text { the cohort }\end{array}$ & 30-days & 365-days & Not deceased \\
\hline & & \multicolumn{4}{|c|}{ Accumulated mortality $n(\%)$} \\
\hline \multicolumn{2}{|l|}{ All operations } & 710 & $101(14.2)$ & $189(26.6)$ & $521(73.4)$ \\
\hline \multicolumn{2}{|l|}{ Primary surgery } & 597 & $85(14.2)$ & $149(25.0)$ & $448(75.0)$ \\
\hline \multicolumn{2}{|l|}{ Re-operation } & 113 & $16(14.2)$ & $39(34.5)$ & $74(65.5)$ \\
\hline \multirow{8}{*}{$\begin{array}{l}\text { Age } \\
\text { Mean age for all operations } 65,6 \text { (years) }\end{array}$} & $18-29$ & 34 & $2(5.9)$ & $2(5.9)$ & $32(94.1)$ \\
\hline & $30-39$ & 39 & $0(0.0)$ & $1(2.6)$ & $38(97.4)$ \\
\hline & $40-49$ & 65 & $2(3.1)$ & $6(9.2)$ & 59 (89.8) \\
\hline & $50-59$ & 92 & $5(5.5)$ & $13(14.2)$ & 79 (85.8) \\
\hline & $60-69$ & 127 & $11(8.7)$ & $25(19.7)$ & $102(80.3)$ \\
\hline & $70-79$ & 164 & $29(17.7)$ & $56(34.1)$ & $108(65.9)$ \\
\hline & $80-89$ & 167 & $41(24.6)$ & $72(43.1)$ & $95(56.9)$ \\
\hline & $90-100$ & 22 & $11(50.0)$ & $14(63.6)$ & $8(36.4)$ \\
\hline \multirow[t]{2}{*}{ Gender } & Female & 393 & $56(14.2)$ & $106(27.0)$ & $287(73.0)$ \\
\hline & Male & 317 & $45(14.2)$ & $83(26.2)$ & $234(73.8)$ \\
\hline \multirow[t]{9}{*}{ Comorbidity $^{a}$} & Yes (one or more) & 368 & $66(17.9)$ & $113(30.7)$ & $255(69.3)$ \\
\hline & None of the below & 342 & $35(10.2)$ & $76(22.2)$ & $266(77.8)$ \\
\hline & COPD & 57 & $17(29.8)$ & $26(45.6)$ & $31(54.4)$ \\
\hline & $\mathrm{IHD}$ & 84 & $25(29.8)$ & $37(44.0)$ & $47(56.0)$ \\
\hline & Heart failure & 63 & $22(34.9)$ & $32(50.8)$ & $31(49.2)$ \\
\hline & Diabetes & 82 & $12(14.3)$ & $30(36.6)$ & $52(63.4)$ \\
\hline & Renal failure & 90 & $25(27.8)$ & $42(46.7)$ & $48(53.3)$ \\
\hline & Obesity & 88 & $9(10.2)$ & $14(15.9)$ & $74(84.1)$ \\
\hline & Smoker & 92 & $11(11.9)$ & $19(20.7)$ & $73(79.7)$ \\
\hline \multicolumn{2}{|l|}{ Cancer diagnosis $^{b}$} & 218 & $33(15.1)$ & $100(45.9)$ & $118(54.1)$ \\
\hline \multirow[t]{5}{*}{ ASA-classification } & ASA 1 & 72 & $2(2,8)$ & $5(6.9)$ & $67(93.1)$ \\
\hline & ASA 2 & 247 & $8(3.2)$ & $24(9.7)$ & $223(90.3)$ \\
\hline & ASA 3 & 282 & $42(14.9)$ & $92(32.6)$ & $190(67.4)$ \\
\hline & ASA 4 & 98 & $44(44.9)$ & $61(62.2)$ & $37(37.8)$ \\
\hline & ASA 5 & 11 & $5(45.5)$ & 7 (63.6) & $4(36.4)$ \\
\hline \multicolumn{2}{|l|}{ Multiple surgery ${ }^{c}$} & 88 & $3(3.4)$ & $12(13.6)$ & $76(86.4)$ \\
\hline \multicolumn{6}{|l|}{ Pathological findings } \\
\hline \multirow[t]{2}{*}{ Ileus } & Small intestine & 334 & $28(8.4)$ & $60(18.0)$ & $274(82.0)$ \\
\hline & Colon & 69 & $9(13.0)$ & $24(34.8)$ & $45(65.2)$ \\
\hline \multirow[t]{4}{*}{ Intestinal perforation } & Colon & 60 & $18(30.0)$ & $24(40.0)$ & $36(60.0)$ \\
\hline & Small intestine & 80 & $19(23.8)$ & $29(36.3)$ & $51(63.7)$ \\
\hline & Ventricle & 56 & $11(19.6)$ & $20(35.7)$ & $36(64.3)$ \\
\hline & Anastomosis leakage & 21 & $4(19.0)$ & $6(28.6)$ & $15(71.4)$ \\
\hline \multirow[t]{3}{*}{ Peritonitis } & Purulent & 43 & $7(16.3)$ & $12(27.9)$ & $31(72.1)$ \\
\hline & Faecal & 57 & $14(24.6)$ & $25(43.9)$ & $32(56.1)$ \\
\hline & Other peritonitis & 87 & $24(27.6)$ & $33(37.9)$ & $54(62.1)$ \\
\hline \multicolumn{2}{|l|}{ Intestinal ischemia/gangrene } & 81 & $21(25.9)$ & $30(37.0)$ & $51(63.0)$ \\
\hline \multicolumn{2}{|l|}{ Abdominal bleeding } & 43 & $10(23.3)$ & $14(32.5)$ & $29(67.5)$ \\
\hline \multicolumn{2}{|l|}{ Trauma laparotomy } & 21 & $2(9.5)$ & $4(19.0)$ & $17(81.0)$ \\
\hline
\end{tabular}

ASA American society of anaesthesiologist-classification of comorbidity

a "Yes" related to comorbidity means that the patient had one or more of the specified comorbidities below. Ischemic heart disease (IHD), chronic obstructive pulmonary disease (COPD), Obesity classified as BMI $>30$

${ }^{\mathrm{b}}$ Cancer diagnosis of any kind from 3 years before until 1 year after surgery

'The cohort contains 41 patients who had EL more than once ( 1 patient had 4 operations, 4 patients had 3 operations and 36 patients had 2 operations), these 41 patients therefore represent 88 operations. Mortality variable has been adjusted so that an expiry only can be attributed as a result to the last of a patients operations 
Table 7 Factors related to mortality in univariate analysis

\begin{tabular}{|c|c|c|c|c|}
\hline \multirow[t]{2}{*}{ Mortality } & & 30 days $(\%)$ & 365 days $(\%)$ & $\mathrm{p}$-value \\
\hline & & \multicolumn{3}{|c|}{ Accumulated mortality } \\
\hline \multirow[t]{2}{*}{ Gender } & Female & 14.2 & 27.0 & 0.695 \\
\hline & Male & 14.2 & 26.2 & \\
\hline \multirow[t]{5}{*}{ ASA-classification } & 1 & 2.8 & 6.9 & $<0.001$ \\
\hline & 2 & 3.2 & 9.7 & \\
\hline & 3 & 14.9 & 32.6 & \\
\hline & 4 & 44.9 & 62.2 & \\
\hline & 5 & 45.5 & 63.6 & \\
\hline \multirow[t]{4}{*}{ Pathology, peritonitis } & None & 10.7 & 22.8 & \\
\hline & Purulent & 16.3 & 27.9 & \\
\hline & Faecal & 24.6 & 43.9 & \\
\hline & Other & 27.6 & 37.9 & $<0.001$ \\
\hline \multirow[t]{2}{*}{ Comorbidity-any } & None & 10.2 & 22.2 & \\
\hline & Yes & 17.9 & 30.7 & 0.020 \\
\hline \multirow[t]{2}{*}{ Renal failure } & None & 12.3 & 24.4 & \\
\hline & Yes & 27.8 & 46.7 & $<0.001$ \\
\hline \multirow[t]{2}{*}{$\mathrm{IHD}$} & None & 12.3 & 25.1 & $<0.001$ \\
\hline & Yes & 29.8 & 44.0 & \\
\hline \multirow[t]{2}{*}{ COPD } & None & 13.0 & 25.9 & 0.008 \\
\hline & Yes & 29.8 & 45.6 & \\
\hline \multirow[t]{2}{*}{ Heart failure } & None & 12.4 & 25.0 & $<0.001$ \\
\hline & Yes & 34.9 & 50.8 & \\
\hline \multirow[t]{2}{*}{ Cancer diagnosis* } & None & 13.8 & 18.1 & $<0.001$ \\
\hline & Yes & 15.1 & 45.9 & \\
\hline \multirow{2}{*}{$\begin{array}{l}\text { Admitted to ICU at } \\
\text { any time }\end{array}$} & None & 7.0 & 19.5 & $<0.001$ \\
\hline & Yes & 37.9 & 52.1 & \\
\hline
\end{tabular}

Univariate analysis performed using Chi2-test. ASA American society of anaesthesiologist-classification of comorbidity. "Comorbidity-any" represents one or more of the following: Renal failure, IHD-ischemic heart disease, COPD - Chronic obstructive pulmonary disease, heart failure, Diabetes, Obesity and smoker. ${ }^{*}$ Cancer diagnosis of any kind from 3 years before until 1 year after surgery. ICU intensive care unit

Table 8 Surgical complications

\begin{tabular}{lllll}
\hline Clavien-Dindo score group & $\begin{array}{l}\text { Missing } \\
\mathbf{n}(\%)\end{array}$ & $\begin{array}{l}\mathbf{1 - 3 a} \\
\mathbf{n}(\%)\end{array}$ & $\begin{array}{l}\mathbf{3 b - 5} \\
\mathbf{n}(\%)\end{array}$ & Total \\
\hline $7(1.0)$ & $440(62.0)$ & $263(37.0)$ & 710 \\
\hline
\end{tabular}

This table shows the proportion of cases that had a surgical complication according to Clavien-Dindo classification. During data collection, a high classification automatically erase a lower

higher mortality. This is-in our interpretation-related to the surgical strategy where the surgeons in our department are less prone to perform an intestinal anastomosis in a patient who is critically ill and with deranged organ functions. Further in-depth-analyses of mortality in relation to confounding factors for patients undergoing EL are needed.
To ensure that no operations were missed or incorrectly selected, all laparotomies were collected, even laparotomies where the primary intervention code was different (i.e. when the surgeon notified the need to operate, the primary plan was to perform another surgical procedure, for example, only a laparoscopy, but a perioperative change of plan led to a laparotomy). All medical records were scrutinised to exclude/include every specific case and this process resulted in the complete list of 710 operations. If the cohort was based exclusively on laparotomy as a surgical procedure in the registers, the cohort would most probably not reflect reality, because operations would probably have been missed or incorrectly included.

It can be argued that the 41 patients that underwent multiple surgeries, thereby representing more than one operation each, change the demographics of the cohort. We believe that unexpected new operations comprising emergency laparotomies are important to include, as the current study focuses heavily on perioperative management. On the other hand, if the unexpected new operations were excluded, the cohort would not reflect reality. However, it is important to adjust outcome variables so that data on time points, complications and mortality are accurate. The inclusion of several operations connected to one individual could skew the mortality data, especially since the study group was chosen to account for the mortality of the last performed laparotomy. It appears that the mortality rate in the group that undergoes multiple surgery is very low and has little impact on the overall mortality for the entire cohort.

This study has several limitations. It is a single-centre study, which risks giving data less external validity. The data in the study are prospectively recorded but retrospectively collected from the patients' medical journals. The validity of data collected in this way depends on the accuracy of medical records, in which hundreds of healthcare professionals have entered information about the patients undergoing surgery. On the other hand, it can be argued that, with so many professionals involved, external validity increases. Moreover, the study period is relatively long, a little more than three years, which offers the scope for changes in treatment during the study period.

Multivariate analyses of the significant results presented here have not been performed. These analyses will be performed when the control cohort can be compared with the intervention group in the SMASH study. In spite of this, the main results presented in this study are consistent with those in previously published studies using comparable populations $[8,10,13,14]$.

In a Swedish context, this cohort study is the first major review of a large population that has undergone EL. 
Acute high-risk abdominal surgery accounts for a considerable proportion of acute surgical care in healthcare systems worldwide [4]. Underlying pathologies are a major contributor to mortality and morbidity in these patients, but studies indicate that standardised management can improve the outcome $[8,13,14,19]$. It is therefore of great importance to further study this group of patients. Our results present the first part of the SMASH project [21], an ongoing study at the Northern Älvsborg County Hospital (NÄL), NU-Hospital Group (Trollhättan, Sweden) exploring whether or not the introduction of a standardised perioperative protocol for high-risk abdominal surgery can affect outcome in a Swedish context.

The EL is a lifesaving procedure and a cornerstone of acute surgical care. Relatively few studies of outcome and perioperative management are carried out and there is a need for more knowledge in the field.

\section{Conclusion}

This study reveals mortality in the same range as previous studies. We perceive that the mortality rate is high and intend to investigate whether the outcome after EL in Sweden can be improved. It has not yet been shown whether this is possible by standardising perioperative care.

\section{Abbreviations \\ EL: Emergency laparotomy; ICU: Intensive care unit; LOS: Length of stay; OT: Operating theatre; NÄL: Norra Älvsborgs County Hospital; C-D: Clavien-Dindo.}

\section{Acknowledgements}

Professor Juri Kartus for overall support. Senior Consultant Isabella Bister for her expert advice. Jenny Roessberg for data support and Jeanette Kliger for linguistic assistance.

\section{Authors' contributions}

$\mathrm{TT}$ is co-responsible for carrying out the study and contributed to much of the collection of data and the writing of the manuscript. GH contributed in collecting of the data and peer review. In her experience NS is an important peer reviewer. OK has contributed with peer review and clinical experience. MP was a major contributor in writing the manuscript and analyse of the dataset. All authors have read and approved the manuscript.

\section{Funding}

Open access funding provided by University of Gothenburg. This work is being supported by the Department of Research and Development, NU Hospital Group. Grants received from the Local Research and Development Council Fyrbodal (VGFOUFBD-803271) and The W\&M Lundgrens Science Foundation (2019-2883). The two funding parties have not had any impact on study design, data collection, analysis or interpretation of results in the study.

\section{Availability of data and materials}

The datasets analysed during the current study are available from the corresponding author on reasonable request.

\section{Declarations}

Ethics approval and consent to participate The study has been approved by the Swedish Ethical Review Authority. Reference number: Dnr: 868-17.
Consent for publication

Not applicable.

\section{Competing interests}

The authors declare that they have no competing interests.

\section{Author details}

'Department of Surgery, Institute of Clinical Sciences, Sahlgrenska Academy, University of Gothenburg, Gothenburg, Sweden. ${ }^{2}$ Department of Research and Development, NU-Hospital Group, Trollhättan, Sweden. ${ }^{3}$ Department of Anesthesiology and Intensive Care Unit, NU-Hospital Group, Trollhättan, Sweden. ${ }^{4}$ Department of Surgery, NU-Hospital Group, Trollhättan, Sweden. ${ }^{5}$ Department of Orthopedics, Institute of Clinical Sciences, Sahlgrenska Academy, University of Gothenburg, Gothenburg, Sweden. ${ }^{6}$ Department of Anesthesiology and Intensive Care, Institute of Clinical Sciences, Sahlgrenska Academy, University of Gothenburg, Gothenburg, Sweden.

Received: 17 March 2021 Accepted: 4 Auqust 2021

Published online: 11 August 2021

References

1. Weiser TG, Haynes AB, Molina G, Lipsitz SR, Esquivel MM, Uribe-Leitz T, et al. Estimate of the global volume of surgery in 2012: an assessment supporting improved health outcomes. Lancet. 2015;385:S11.

2. Pearse RM, Harrison DA, James P, Watson D, Hinds C, Rhodes A, et al. Identification and characterisation of the high-risk surgical population in the United Kingdom. Crit Care (London, England). 2006;10(3):R81.

3. Ho VP, Schiltz NK, Reimer AP, Madigan EA, Koroukian SM. High-risk comorbidity combinations in older patients undergoing emergency general surgery. J Am Geriatr Soc. 2019;67(3):503-10.

4. Scott JW, Olufajo OA, Brat GA, Rose JA, Zogg CK, Haider AH, et al. Use of national burden to define operative emergency general surgery. JAMA Surg. 2016;151(6): e160480.

5. Bampoe S, Odor PM, Ramani Moonesinghe S, Dickinson M. A systematic review and overview of health economic evaluations of emergency laparotomy. Perioper Med (Lond). 2017;6:21.

6. Al-Temimi MH, Griffee M, Enniss TM, Preston R, Vargo D, Overton S, et al. When is death inevitable after emergency laparotomy? Analysis of the American College of Surgeons National Surgical Quality Improvement Program database. J Am Coll Surg. 2012;215(4):503-11.

7. Aitken RM, Partridge JSL, Oliver CM, Murray D, Hare S, Lockwood S, et al. Older patients undergoing emergency laparotomy: observations from the National Emergency Laparotomy Audit (NELA) years 1-4. Age Ageing. 2020;49(4):656-63.

8. Aggarwal G, Peden CJ, Mohammed MA, Pullyblank A, Williams B, Stephens $T$, et al. Evaluation of the collaborative use of an evidence-based care bundle in emergency laparotomy. JAMA Surg. 2019;154(5): e190145.

9. Barazanchi AWH, Xia W, MacFater W, Bhat S, MacFater H, Taneja A, et al. Risk factors for mortality after emergency laparotomy: scoping systematic review. ANZ J Surg. 2020. https://doi.org/10.1111/ans.16082.

10. Vester-Andersen $M$, Lundstrom LH, Moller MH, Waldau T, Rosenberg J, Moller AM. Mortality and postoperative care pathways after emergency gastrointestinal surgery in 2904 patients: a population-based cohort study. Br J Anaesth. 2014;112(5):860-70.

11. Peden CJ, Stephens T, Martin G, Kahan BC, Thomson A, Rivett K, et al. Effectiveness of a national quality improvement programme to improve survival after emergency abdominal surgery (EPOCH): a stepped-wedge cluster-randomised trial. Lancet (London, England). 2019;393(10187):2213-21.

12. Peden C, Scott MJ. Anesthesia for emergency abdominal surgery. Anesthesiol Clin. 2015;33(1):209-21.

13. Tengberg LT, Bay-Nielsen M, Bisgaard T, Cihoric M, Lauritsen ML, Foss NB. Multidisciplinary perioperative protocol in patients undergoing acute high-risk abdominal surgery. Br J Surg. 2017;104(4):463-71.

14. Huddart S, Peden CJ, Swart M, McCormick B, Dickinson M, Mohammed $M A$, et al. Use of a pathway quality improvement care bundle to reduce mortality after emergency laparotomy. Br J Surg. 2015;102(1):57-66. 
15. Sankar A, Johnson SR, Beattie WS, Tait G, Wijeysundera DN. Reliability of the American Society of Anesthesiologists physical status scale in clinical practice. Br J Anaesth. 2014;113(3):424-32.

16. Akhtar M, Donnachie DJ, Siddiqui Z, Ali N, Uppara M. Hierarchical regression of ASA prediction model in predicting mortality prior to performing emergency laparotomy a systematic review. Ann Med Surg (Lond). 2020;60:743-9.

17. Clavien PA, Barkun J, de Oliveira ML, Vauthey JN, Dindo D, Schulick RD, et al. The Clavien-Dindo classification of surgical complications: five-year experience. Ann Surg. 2009;250(2):187-96.

18. Peacock O, Bassett MG, Kuryba A, Walker K, Davies E, Anderson I, et al. Thirty-day mortality in patients undergoing laparotomy for small bowel obstruction. Br J Surg. 2018;105(8):1006-13.

19. Saunders DI, Murray D, Pichel AC, Varley S, Peden CJ. Variations in mortality after emergency laparotomy: the first report of the UK Emergency Laparotomy Network. Br J Anaesth. 2012;109(3):368-75.
20. Tolstrup MB, Watt SK, Gogenur I. Morbidity and mortality rates after emergency abdominal surgery: an analysis of 4346 patients scheduled for emergency laparotomy or laparoscopy. Langenbecks Arch Surg. 2017:402(4):615-23.

21. Timan TJ, Sernert N, Karlsson O, Prytz M. SMASH standardised perioperative management of patients operated with acute abdominal surgery in a high-risk setting. BMC Res Notes. 2020. https://doi.org/10.1186/ s13104-020-05030-4.

\section{Publisher's Note}

Springer Nature remains neutral with regard to jurisdictional claims in published maps and institutional affiliations.
Ready to submit your research? Choose BMC and benefit from:

- fast, convenient online submission

- thorough peer review by experienced researchers in your field

- rapid publication on acceptance

- support for research data, including large and complex data types

- gold Open Access which fosters wider collaboration and increased citations

- maximum visibility for your research: over $100 \mathrm{M}$ website views per year

At BMC, research is always in progress.

Learn more biomedcentral.com/submissions 